\title{
Modeling the Fate and Transport of Plastic Debris in Freshwaters: Review and Guidance
}

\author{
Merel Kooi, Ellen Besseling, Carolien Kroeze, Annemarie P. van Wezel, \\ and Albert A. Koelmans
}

\begin{abstract}
Contamination with plastic debris has been recognized as one of today's major environmental quality problems. Because most of the sources are land based, concerns are increasingly focused on the freshwater and terrestrial environment. Fate and transport models for plastic debris can complement information from measurements and will play an important role in the prospective risk assessment of plastic debris. We review the present knowledge with respect to fate and transport modeling of plastic debris in freshwater catchment areas, focusing especially on nano- and microplastics. Starting with a brief overview of theory and models for nonplastic particles, we discuss plastic-specific properties, processes, and existing mass-balance-, multimedia-, and spatiotemporally explicit fate models. We find that generally many theoretical and conceptual approaches from
\end{abstract}

\footnotetext{
This chapter has been externally peer reviewed.
}

The original version of this chapter was revised. An erratum to this chapter can be found at DOI 10.1007/978-3-319-61615-5_14.

M. Kooi $(\bowtie)$

Aquatic Ecology and Water Quality Management Group, Wageningen University \& Research, 6700 AA, Wageningen, Netherlands

e-mail:merel.kooi@wur.nl

E. Besseling and A.A. Koelmans

Aquatic Ecology and Water Quality Management Group, Wageningen University \& Research, 6700 AA, Wageningen, Netherlands

Wageningen Marine Research, 1970 AB IJmuiden, Netherlands

C. Kroeze

Water Systems and Global Change Group, Wageningen University \& Research, 6700 AA, Wageningen, Netherlands

A.P. van Wezel

KWR Watercycle Research Institute, Nieuwegein, Netherlands

Copernicus Institute, Utrecht University, Utrecht, Netherlands 
models developed earlier for other types of (low density) particles apply also to plastic debris. A unique feature of plastic debris, however, is its combination of high persistence, low density, and extremely wide size distribution, ranging from the nanometer to the $>\mathrm{cm}$ scale. This causes the system behavior of plastic debris to show a far wider variety than most other materials or chemicals. We provide recommendations for further development of these models and implications and guidance for how fate and transport models can be used in a framework for the tiered risk assessment of plastic debris.

Keywords Fate, Freshwater, Microplastics, Modeling, Nanoplastics

\section{Introduction}

Contamination of the environment with plastic debris has received increasing attention from the public, environmentalists, scientists, and policy makers since the 1970s $[1,2]$. Model predictions suggest that currently over 5 trillion plastic particles float on the ocean surface [3] and that in 2010 alone between 4.8 and 12.7 million metric tons of plastic entered the ocean [4]. Plastics occur in a wide range of sizes, and particles can therefore be ingested by a variety of terrestrial [5] and aquatic species [6]. Ingestion of microplastics, particles $<5 \mathrm{~mm}$ in length [1], can negatively affect hatching, growth rates, and food ingestion [7, 8]. Besides the potential effect of ingestion, plastic particles can act as vectors for organic pollutants [9] or function as floaters for (invasive) rafting species [10]. The occurrence and distribution of plastic debris in the marine environment has been studied even in the most remote areas, such as the arctic [11] and the ocean floor [12]. However, even though rivers are recognized as a major source of marine litter [13-15], the occurrence of plastic debris in freshwater systems just started to receive attention $[16,17]$.

Microplastics have been found in freshwater systems around the world, as summarized in a recent review by Eerkes-Medrano et al. [17]. Occurrence of microplastics in freshwater systems ranges from remote lakes [18] to industrial rivers such as the Rhine [15, 19] or St. Lawrence River [20]. Sources of plastic debris in freshwater systems have not been studied extensively but likely include effluents from wastewater treatment plants (WWTP), sewage sludge, shipping activities, atmospheric fallout, direct disposal from the public, beach littering, and runoff from agricultural, recreational, industrial, and urban areas [16, 21]. High loads are estimated to enter the marine environment: for example, an average of $1,533 \mathrm{t}$ plastic per year was estimated to enter the Black Sea from the Danube [13], and an average of $208 \mathrm{t}$ plastic per year was estimated to enter the Mediterranean from the Rhone [22]. However, river loads exhibit a high degree of variation. For example, rain events were shown to increase the plastic concentration up to 150 times in an urban part of the Rhone catchment [22]. Also, total loads in the Danube varied between $10.9 \pm 43.6$ and $2.2 \pm 3.0 \mathrm{~g}$ (mean $\pm \mathrm{SD}$ ) per $1,000 \mathrm{~m}^{3}$ from 2010 to 2012 [13], indicating both the uncertainty in the load estimates and the temporal change of plastic loads. Transport of plastic near the bottom of the river 
[23], plastic deposited in river sediments [15], and fragmentation increase the uncertainty with respect to loads even further.

Besides microplastics, nanoplastics are likely to be present in the freshwater environment [24]. No formal size definition has been set for nanoplastics, resulting in different classifications such as $<100 \mathrm{~nm}[24,25],<1 \mu \mathrm{m}$ [26], and $<20 \mu \mathrm{m}$ [16]. Hereafter, we will use $<100 \mathrm{~nm}$ as a size cutoff for nanoplastics, to comply with the definition of engineered nanoparticles [24]. Nanoplastics can be either directly released into to the environment (e.g., as a by-product of thermal cutting, 3D printing) or indirectly via the degradation of larger plastics [24, 27-29]. Several studies have shown that nanoplastics can be ingested by a variety of organisms, although systematic effects remain unknown (summarized in [24, 30]). Despite the attention to plastic pollution and the potential harm it causes in the environment, to date no proper environmental risk assessment (ERA) framework is available for this anthropogenic pollutant. So far, microplastics have been found to be ingested by freshwater organisms such as fish [31-33] and mud snails [34] (see [8] for further detail). However, effect assessments are scarcely done for freshwater species $[16,17]$. Retrospective exposure assessments have also not been done yet for plastic debris, because of the difficult, time-consuming, and costly detection methods currently available. However, exposure assessments can also be based on quantitative model estimates of plastic debris loads and distributions. To our knowledge, only one transport-fate model has been developed for plastic debris from nano- to 1-cm-sized particles [35, 36], one for microplastics [37] in rivers, and none for lakes. However, other types of models simulating particle transport in rivers do exist, and they can be used as inspiration for new plastic debris transport models for the freshwater environment.

The aims of this review are (a) to identify how existing particle transport models can serve as examples for new plastic transport models, (b) to identify the properties and processes that are relevant for the modeling of plastic debris in freshwater systems, (c) to review the existing models that (to some extent) already take into account these properties and processes, and (d) to provide recommendations for the further development of these models and guidance of how these models can be used in the framework of an ERA. We first briefly discuss existing particle transport and fate models for different particle types such as sediment or organic matter (Sect. 2). We identify what characterizes plastic debris from a transport modeling perspective and how this differs from other (traditional, natural) particles (Sect. 3), followed by a critical review of the fate models for freshwater systems published in the peerreviewed literature (Sect. 4). In Sect. 5, we include a short review on data and knowledge gaps in relation to plastic modeling and discuss what kind of model categories are highly relevant for plastic debris. We also discuss the possible role of fate modeling in a future risk assessment framework for plastic debris in freshwater systems. The terms "plastic debris," "plastics," and "plastic particles" are used interchangeably in this review and do not refer to a specific size class. Macroplastics, microplastics, and nanoplastics refer to particles $>5 \mathrm{~mm}$ in size, particles between 5 and $100 \mathrm{~nm}$ in size, and particles $<100 \mathrm{~nm}$, respectively. 


\section{Modeling the Transport of Particles in Aquatic Systems}

Few models exist that simulate the transport and fate of plastic debris in freshwater systems. Plastic debris includes buoyant macroplastic items like bottles, food wrappers and containers, plastic cutlery, and expanded polystyrene (PS), larger polyethylene (PE), or polypropylene (PP) items that float at the surface $[13,38]$ and will be transported under the influence of water flow and wind (discussed in Sect. 4 and Fig. 1). Non-buoyant plastics or buoyant plastics that become more susceptible to vertical mixing due to their small size (i.e., microplastic and nanoplastic) will become submerged and may be subject to settling in a fashion similar to that of natural colloids and suspended solids (Fig. 2). Hence, such natural particles may serve as a proxy for some classes of plastic debris, and models simulating the transport of such natural particles can form the basis for the development of transport models for plastic debris. In this section, we summarize modeling methods for (submerged) particles in freshwater systems in general. This includes how different materials, aquatic systems, processes, and scales can be modeled. It is beyond the scope of this review to strive for completeness with respect to the large number of specific particle transport models that have been presented before, especially since excellent reviews on transport models already exist for sediment [39-42], algae [43], microorganisms [44], and nanomaterials [45, 46]. These reviews describe the present top models such as SWAT, WASP, HSPF, ANSWERS, and WEPP, all of which include suspended solids [39, 42].

Key Processes Affecting Particle Transport in Freshwater Systems Particles can enter an aquatic system via external inputs including, for example, WWTP

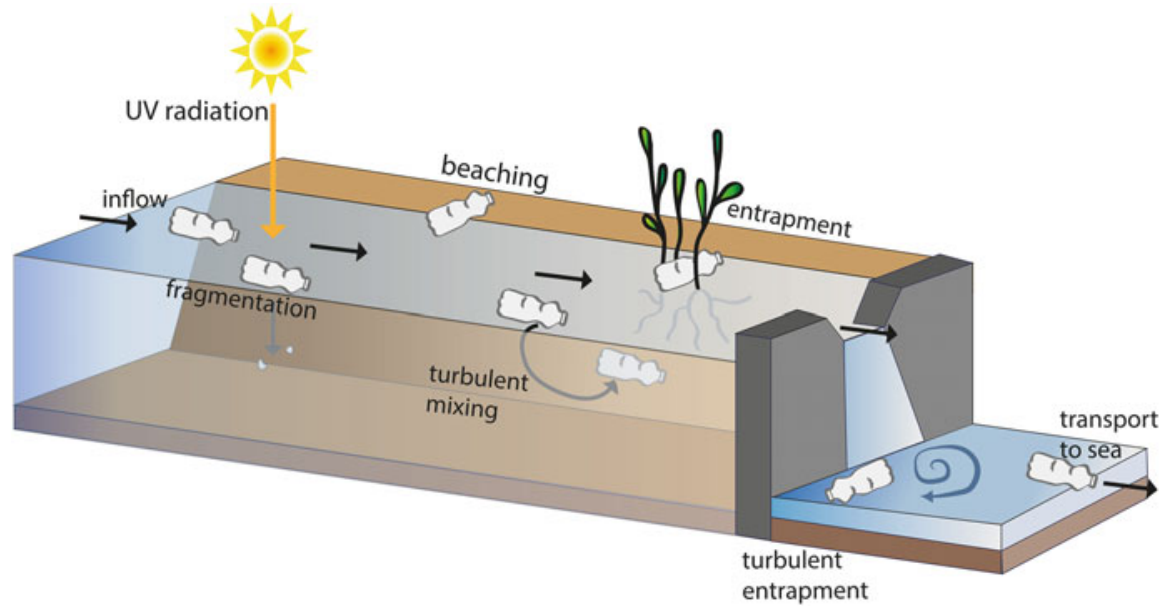

Fig. 1 Schematic representation of the different processes playing a role in the transport of macroplastic in a river and lake. Turbulent water movement below a weir can "capture" plastic debris for a certain period of time. The scaling of the different components is not representative, and not all processes happen to each plastic piece or in a fixed order 

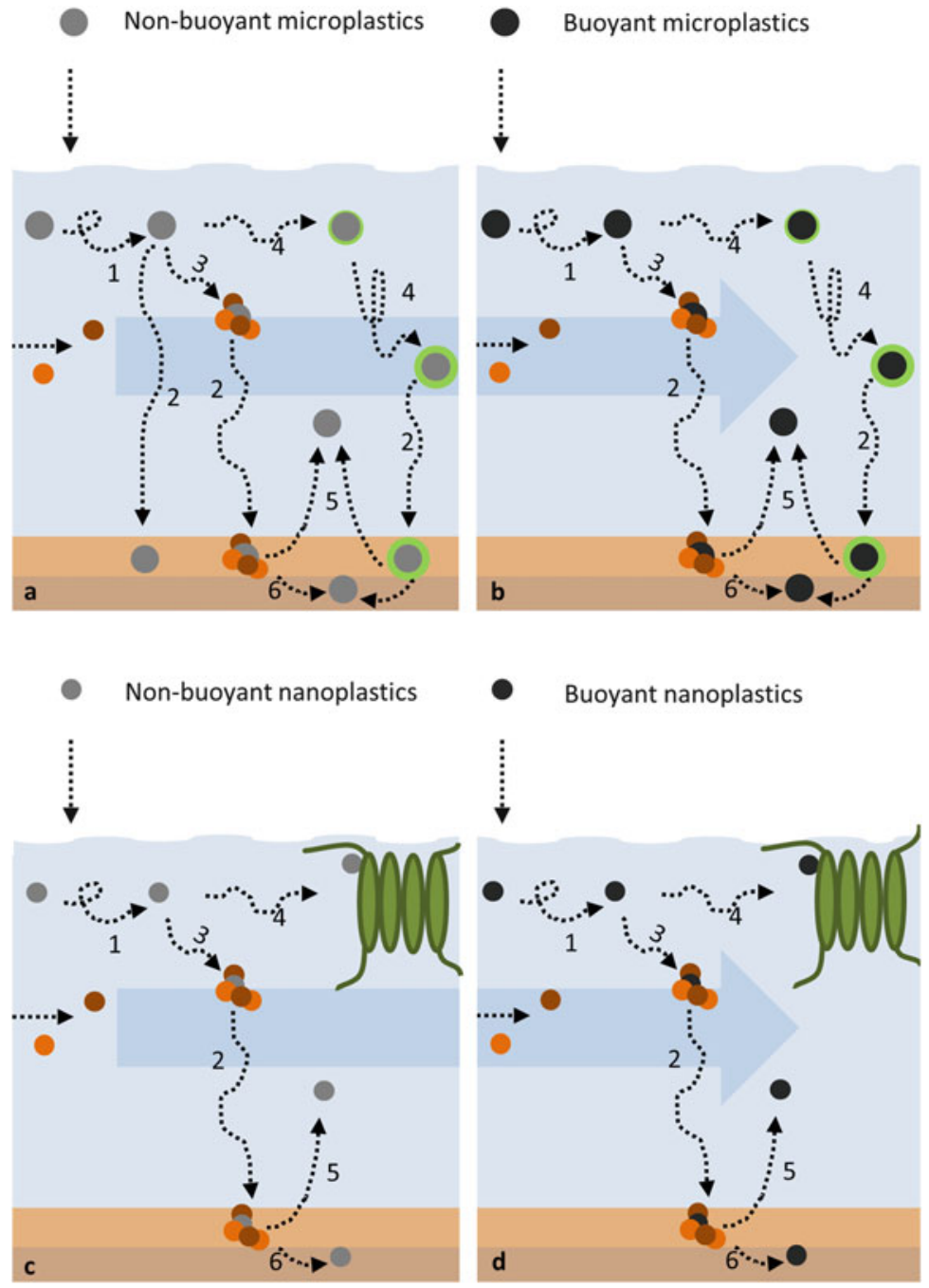

Fig. 2 Schematic representation of the key different processes playing a role in the transport of non-buoyant microplastics (a), buoyant microplastics (b), non-buoyant nanoplastics (c), and buoyant nanoplastics (d) in a river or lake. Processes include (1) turbulent transport, (2) settling, (3) aggregation, (4) biofouling, (5) resuspension, and (6) burial. Aggregates can be formed with, for example, sediment, algae, organic matter, or dissolved substances. The scaling of the different components is not representative, and not all processes happen to each particle or in a certain order. Other processes, such as removal by ingestion, relocation, and hydrodynamic alteration by ingestion and excretion (e.g., zooplankton, mussels), can also affect particle fate but are not depicted here

effluents, atmospheric deposition, groundwater, or surface runoff [16, 21]. Several fundamental processes drive the subsequent transport of particles in streams. In fluid mechanics, the collective motion of particles in a fluid is the result of 
advective, dispersive, and diffusive mass transfer. Advection refers to the longitudinal transport based on the average flow velocity. Dispersive mass transfer is the turbulent spreading of mass from highly concentrated areas to less concentrated areas [47]. This results from nonideal flow patterns (i.e., deviations from plug flow) and is a macroscopic phenomenon. Dispersion is multidirectional, as it covers the distribution of all flow directions and velocities [48]. Diffusion is the transport of particles from a high to a low concentration caused by random molecular (Brownian) motion, which is a microscopic phenomenon. The combined transport of substances in rivers due to advection and dispersion is commonly described by the one-dimensional advection-dispersion equation [49, 50]. Besides being transported in the water, suspended solids can be removed from the fluid by settling, which can be modeled with Stokes law or a modification of that law [51, 52]. Particles and substances can reenter the water column by erosion/resuspension of the riverbed. Advection, dispersion, diffusion, settling, and resuspension depend on particle properties such as size, density, shape, fractal dimension, and porosity [5355]. During transport, the aforementioned particle properties can change due to aggregation or biofouling, which will further influence their fate [56-58]. Aggregation is usually modeled using a von Smoluchowski particle interaction model where the formation of aggregates is described kinetically as a function of the colliding particle concentrations, their sizes and densities, their collision frequencies, and attachment efficiencies [56, 59, 60]. Many studies assume spherical particles or aggregates, although it has been suggested that fractal dimensions should be included in these models [52,61]. For aggregates, this would result in more realistic collision radii and hydrodynamics, therewith providing better collision frequency and sedimentation estimates [61]. The relative importance of the different transport processes is dependent on the particle properties. For example, Brownian motion is important for nanoparticle aggregation $[36,56]$, whereas it will be negligible when studying the transport of larger particles [47]. Likewise, biofouling has a faster effect on the buoyancy of microscopic particles, which have a large surface-tovolume ratio, compared to macroscopic particles [62].

Type of Aquatic System Several system properties affect the occurrence of the abovementioned processes. Transport of particles in rivers and lakes differs in many aspects. Rivers have a downstream discharge driven by an elevation gradient. Although natural rivers are turbulent, the time-averaged motion of the water is in the longitudinal direction. In rivers, the advection flow component is usually higher than the dispersion component [47]. Due to sedimentation and burial of suspended solids and associated contaminants, rivers often act as a sink for these contaminants. Compared to rivers, lakes have a very low, if any, flow velocity, enhancing sedimentation processes. Water residence times can be days to $>10^{3}$ years [63] compared to days or weeks in rivers. Therefore, biological and chemical processes are usually more important for the fate of particles in lakes. Mixing processes in lakes, and therefore the importance of sedimentation versus resuspension, can be complex to model because of vertical stratification, the effect of wind, and the lake geometry [47]. Dams in rivers or lakes can increase the water retention time and 
lower the flow velocity, enhancing sedimentation of suspended solids [64]. Also, water withdrawal for various human uses [65, 66], which is highly different for different regions [67], influences the fate of plastics as these abstracted particles are no longer carried to the ocean.

Particle Type With respect to modeling natural particles in freshwater systems, different particle types can be distinguished, such as sediment $[39,68,69]$, algae [43], microorganisms [44], particulate organic matter [70, 71], nanoparticles [59, 63, 72, 73], and seeds [74]. The properties of these materials, such as size, shape, density, porosity, fractal dimension, and attachment efficiency, influence their hydrodynamic behavior and thereby their fate [75]. Some of them approach the properties of categories of plastic particles, which may cause them to have similar hydrodynamic behavior and a mutual applicability of modeling approaches and results. For instance, some plastic particles may become captured in low-density aggregates or flocs, as has been shown for the marine environment $[57,76]$, which affects the hydrodynamics of the resulting new composite particles $[77,78]$. This implies that the transport of the plastic-inclusive floc or aggregate may become indistinguishable from that of a fully natural floc or aggregate. The implications of similarities and differences of plastic compared to natural solid materials for fate and transport will be further discussed in the next section.

\section{Plastic Debris: Properties and Processes Relevant for Fate Modeling}

Key Properties Relevant for Fate Modeling Plastic debris comprises a highly diverse mixture of particle sizes and shapes, made out of different polymers. The size ranges from $>10 \mathrm{~cm}$ for fishing nets, bottles, and plastic bags to nanosized particles $<100 \mathrm{~nm}$. Nanoplastics have so far not been detected in natural waters but are likely to be present $[24,36]$. The density of plastics ranges from $50 \mathrm{~kg} \mathrm{~m}^{-3}$ for extruded polystyrene foam to $1,400 \mathrm{~kg} \mathrm{~m}^{-3}$ for PVC. It can be expected that the composition of plastic in rivers is related to the production volumes of the different polymers, of which polyethylene (38\%), polypropylene (24\%), PVC (19\%), and polystyrene (6\%) are produced most [1]. Recent data partly confirmed these relative proportions of polymers in river sediments of the river Rhine [15], in the reservoir of the Three Gorges Dam [79], and floating on the river Seine [38]. Besides the size and density, the shape of plastics is also highly variable, ranging from small lines and fibers to irregular fragments to granules [80]. Microplastics have often been classified as fragments, fibers, spheres, pellets, lines, sheets, flakes, and foam $[13,15,22,79,81]$, of which fragments are most abundant $[15,22,79]$. The size, shape, and density of particles will influence their transport behavior and fate in the aquatic environment. 
The unique nature of plastic debris can be illustrated by comparison with properties of other types of particles present in water systems. Plastic can be considered to be unique with respect to fate processes because:

- Other particles can be similar sized but then have higher density (metal-based nanoparticles and colloids, suspended sediments, clays, minerals).

- Other particles can have similar density but are far less persistent (wood, algae, detritus, exopolymers, organic matter flocs, or organic colloids).

- Other particles do not exist in a $\mathrm{nm}$ to $>\mathrm{cm}$ size range with all other properties being similar to those of plastics.

We argue that the combination of low density (often near that of water), persistence, wide size range, and variable shape is what makes plastic particles and thus fate model simulation results different from those for other particles. At the same time, low-density nanomaterials (fullerenes, carbon nanotubes) or natural organic particles like cellulose can have a hydrodynamic behavior similar to that of some specific plastic particles.

Processes Specifically Relevant for the Modeling of Plastic Debris Once in the aquatic environment, plastics will be transported downstream. Floating macroplastic can be assumed to be transported with the flow (Fig. 1), i.e., to estuaries, to sea, or to lake reservoirs, where reduced flow conditions, fouling, embrittlement, and fragmentation may trigger sedimentation and further dispersion. Larger items will also accumulate on riverbanks due to wind or reduced flow or dispersive flow patterns in river bends. Vegetation or trees near the shores may serve as a temporary sink for large plastic debris [82], which later on may be released again to the main stream. Non-buoyant plastic debris is subject to the advective, dispersive, and sedimentation processes as described in the previous section. A unique feature here is that a high proportion of the plastic will have a density not that different from that of water, in contrast to natural suspended (mineral) solid particles of the same size. The variety of plastic sizes and densities, however, still varies enormously, leading to a wide variety of transport patterns for individual particles in the mixture.

Biofouling of plastics has been reported for freshwater samples [83, 84] and also is a well-researched phenomenon in marine waters [57, 58, 62, 84]. Plastic debris of all sizes and densities will be fouled and colonized by microbes, forming biofilms, which can lead to significant changes in particle buoyancy. For instance, increased settling as a result of biofouling has recently been shown for marine particles $[57,58,62]$, and it is plausible that the same holds for plastics in the freshwater environment (Fig. 2). The recent detection of microplastics in rivers and lake sediment $[15,20,85]$ confirms that particles with a density higher as well as lower than water can settle and be buried in the sediment. Recent model analysis showed that this also can be explained on a theoretical basis [35, 36]. Buoyant plastics will only settle when they are incorporated in aggregates with a density larger than the water density. This is an important phenomenon, which is 
mechanistically explained by biofouling causing an overall increase in density and attachment efficiency with other particles. Heteroaggregation with natural colloids, clays, and other high-density suspended particles will lead to faster sedimentation of the plastic particles that are captured in the aggregate [35, 36] (Fig. 2).

Another unique feature is the high persistence of plastic. Other particles with similar density and size, e.g., wood, algae, detritus, or other natural organic matter solids, disappear through degradation and mineralization within rather short time scales. Plastic debris however, once buried in the sediment, will only be mineralized on very long time scales, rendering them highly accumulative, bioavailable, and also subject to further transport. As long as plastic particles are close to the sediment surface, they can be resuspended if the flow velocity is high enough to exceed the critical shear stress [86]. However, after prolonged sedimentation, the particles could become "buried." Buried plastic debris would not resuspend anymore, unless turbulence would increase sharply due to storm events or flash floods, for example.

In the laboratory under accelerated weathering conditions, plastics have been shown to become brittle and fragment [28], and it is likely that this also occurs in freshwater systems. This process however is very slow in nature [87] and probably much slower than the typical residence times of plastic in rivers. In lakes with a large retention time, weathering is potentially important though. Fragmentation is caused by photodegradation, thermo-oxidation, hydrolysis, physical abrasion, and/or biodegradation $[1,88]$. Most of these processes require either light, friction, or oxygen to act on the surfaces of the particles, which implies that once buried in anoxic sediment layers, plastic will be preserved for at least decades [89]. Several model categories exist that can use the above mechanistic evidence to simulate the fate of plastic debris in rivers, some of which already have been published in the literature $[36,37,72]$.

\section{Models for Fate and Transport of Microplastics in Freshwater Systems}

In this section, four categories of models will be discussed: emission-based mass balance modeling, global modeling, multimedia modeling, and spatiotemporally explicit modeling. The models differ in their aim, design, scale, level of detail, and state of validation (Table 1). We classified the models based on their major characteristics, but some overlap in these classifications can be found. For example, a global model can also be referred to as spatiotemporally explicit yet on a much larger scale, and a small-scale spatiotemporally explicit model can cover plastic transport in water and sediment, rendering it "multimedia." 


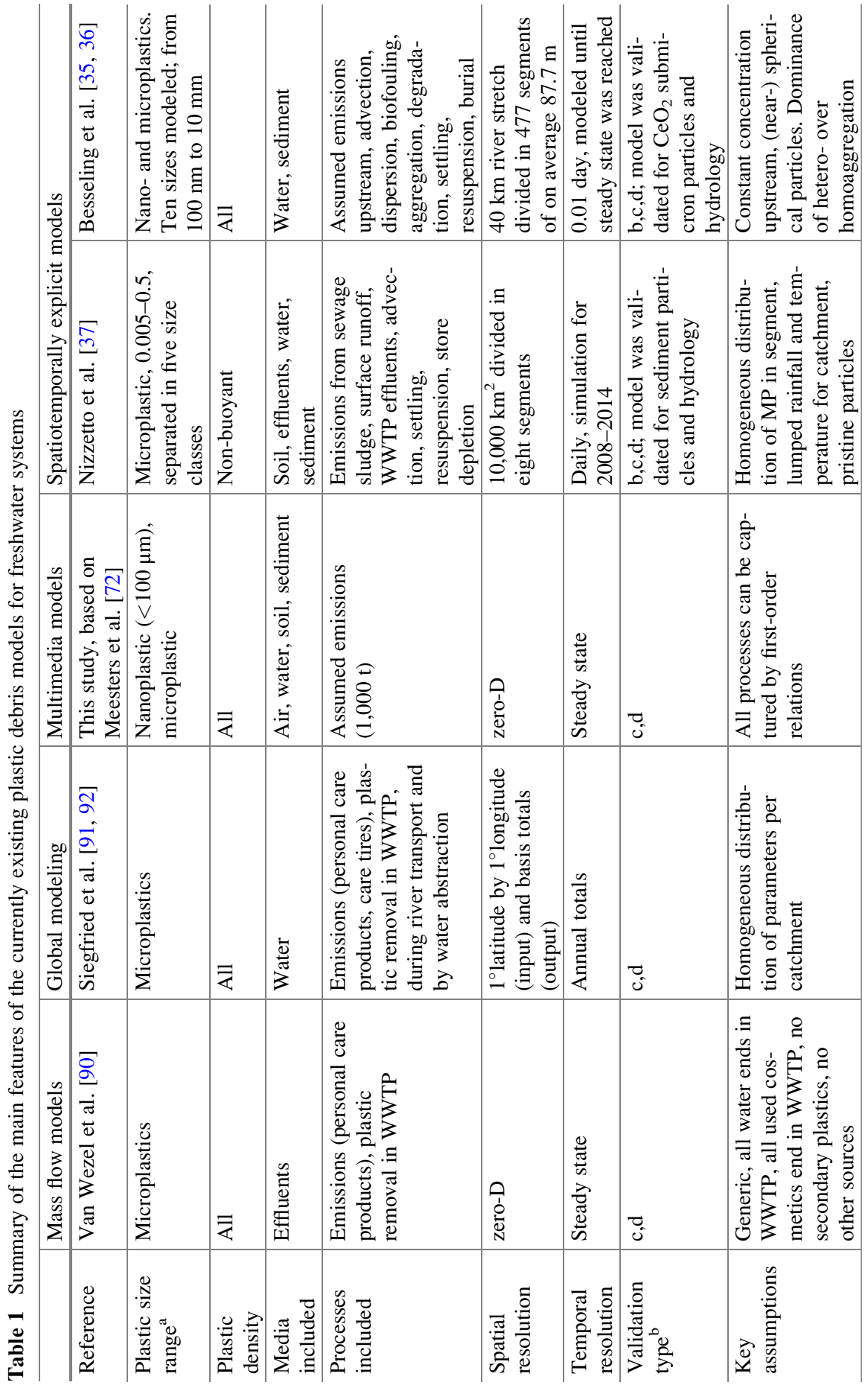




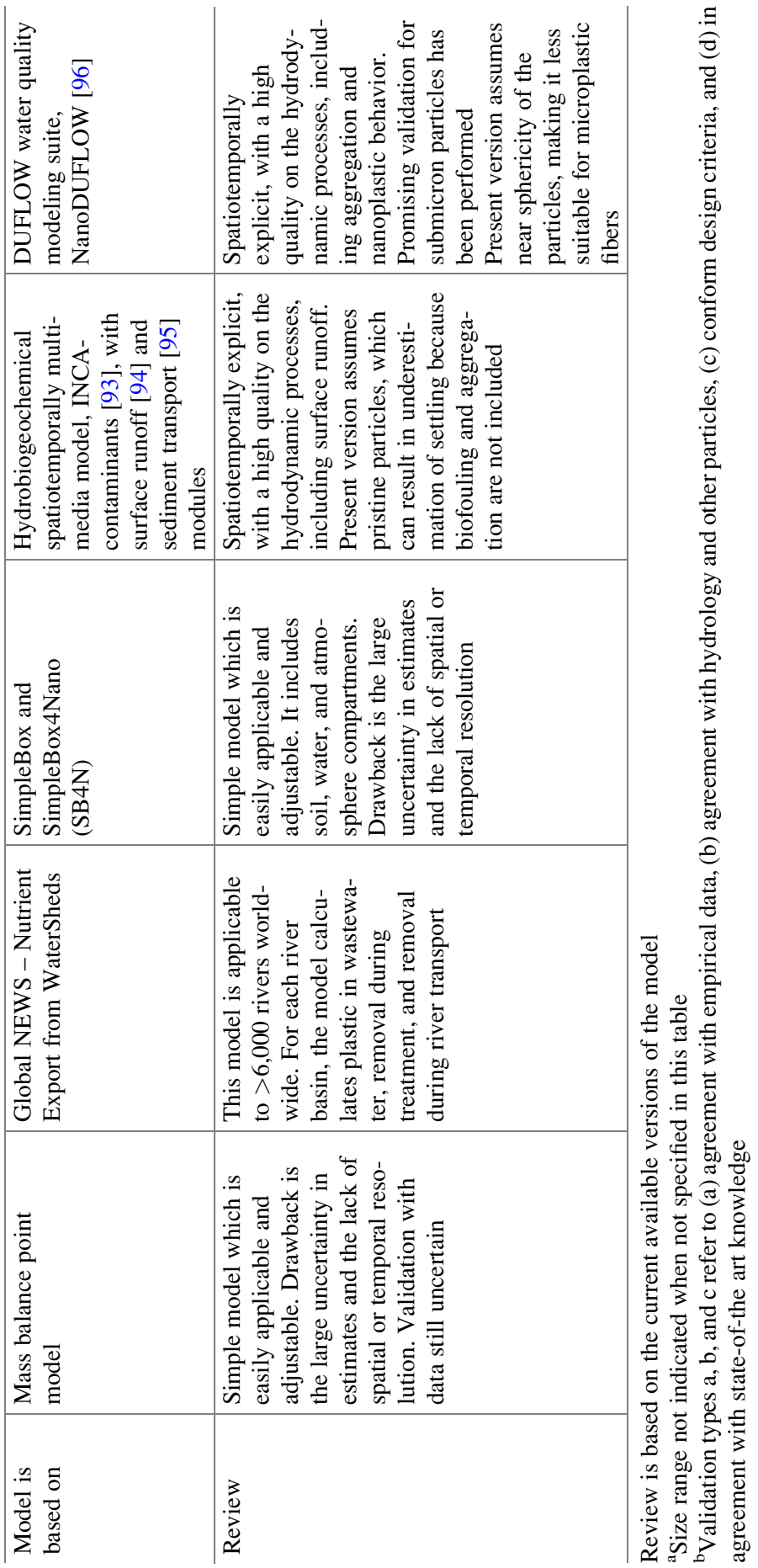




\subsection{Emission-Based Mass Flow Modeling}

Emission-based mass flow or mass balance models have been used for chemicals [97] and have recently been implemented for engineered nanoparticles as well $[45,98,99]$. The latter category of models is of particular interest for this review, because mass flow models for plastic particles can relatively easily be developed along the same lines. Based on estimates of nanoparticle emissions from products, environmental fluxes are calculated to the major compartments like air, soil, water, sediment, and several technical compartments [45]. The compartments typically are considered homogeneous and well mixed [45, 98]. Deposition and removal of particles within compartments are modeled as constant annual flows into a sub-compartment of each box considered. Similar mass flow model applications that calculate environmental concentration for plastic debris in all media (air, soil, water, and sediment) have not been published yet. However, the essence of the approach has been used to estimate concentrations of microplastics from cosmetics in WWTP effluents in the Netherlands [90] and mass emissions of microplastics from cosmetics from Europe to the North Sea [100]. The first study is discussed in detail below.

Mass Flow Modeling of Microplastic Concentrations in WWTP Effluents With the use of a mass flow modeling approach, Van Wezel et al. [90] estimated the emission of microplastics from consumer products to the surface water via WWTP effluents (Table 1). Based on the known use of microplastics in cosmetics and personal care products, cleaning agents, and paints and coatings, emissions were estimated. Per product category, data on the use of the product, the market penetration, and concentration of microplastics in the product were collected. It was estimated that during the wastewater treatment, between 40 and $96 \%$ of the microplastics would be retained by the WWTP. The model calculated the predicted concentration of microplastics in a WWTP effluent as the product of the concentration of microplastics in a product, the daily usage of that product, the fraction of microplastics removed during the wastewater treatment, and the market penetration of the products, divided by the volume of wastewater produced. The estimated effluent concentration of microplastic ranged from $0.2 \mu \mathrm{g} \mathrm{L}^{-1}$ for the conservative estimate to $66 \mu \mathrm{g} \mathrm{L}^{-1}$ for the maximum scenario.

Measured concentrations of microplastics in WWTP effluents range from 20 to 150 particles $\mathrm{L}^{-1}$, as reported after a Dutch monitoring campaign [90]. These particle numbers were converted to mass, based on the size range, the volume assuming cubic shapes, and an average density. To validate the model, the model outcomes were compared with the observations of the monitoring [90]. Three different particle number-to-mass conversion categories were used, classified at "little and light," "intermediate," and "big and heavy" particles, the names relating to the assumed particle size, volume, and density. The model coincided best with observations when "big and heavy" particles were assumed to be measured, that is, particles with a relatively high density, large size, and large volume. However, the 
measured concentrations include both primary and secondary plastics (i.e., produced and fragmented/weathered particles, respectively), whereas the model only included primary plastics, which may have interfered with the reported validation.

Current knowledge on the use of nano- and microplastics in consumer products is limited, so a generic approach with many assumptions was used in this mass flow modeling study, contrasting with the approaches used with more advanced multimedia mass balance models, life cycle perspective models, or probabilistic material flow models. More reliable data to feed the models are needed to improve the emission estimates [90].

\subsection{Global River Models}

River pollution is a worldwide problem. Human activities on the land pollute rivers in all continents. A number of global river pollution models exist. One of these is the Global NEWS (Nutrient Export from WaterSheds) model [101, 102]. Global NEWS is a model that calculates river export of nutrients from land to sea as a function of human activities on the land. Global NEWS includes more than 6,000 river basins using hydrology from the water balance model [103]. It calculates river export at the river mouth. The model input is mostly on a grid of 1 degree longitude by 1 degree latitude. It has been used to simulate trends in river pollution for the period 1970-2050, taking into account change in land use, food production, urbanization, and hydrology [103-105]. Results indicate that over time, most rivers worldwide become more polluted.

Global river export models for nutrients, like Global NEWS, have been under development for more than 20 years. For other pollutants global river export models do not have such a long history. As a result, the Global NEWS approach has been taken as an example and inspiration for other pollutants [44]. Nutrients in rivers can have point sources (e.g., pipes draining into the river) or diffuse sources (e.g., runoff from soils or atmospheric deposition [65]). This is the case for nutrients, but also for other pollutants, like plastic debris. Model structures for point sources of one pollutant can easily serve as an example for other pollutants. The same holds for diffuse sources.

A river export model for microplastics, inspired by the Global NEWS model, is currently under development (Table 1). Preliminary results for point source inputs of microplastics to European seas have been presented [91]. This plastic model calculates point source inputs of microplastics from sewage to rivers. In addition, it simulates river transport of microplastics as a function of population, sewage connection, wastewater treatment, and river retention. River retention is derived from [36]. First results indicate that car tires are important point source inputs of microplastics in European rivers. 


\subsection{Multimedia Modeling}

Multimedia models for chemicals are built by setting up a mass balance equation for each compartment that calculates the fluxes of transport via all exchange processes among compartments that are considered relevant. The fluxes are calculated based on first-order kinetic process rate parameters and concentration or fugacity gradients. The model equations are commonly solved by simple matrix algebra assuming steady state, but they also can be temporally resolved. Common multimedia models for nanosized particles are MendNano [106] and SimpleBox4Nano (SB4N) [72, 73]. These models calculate steady-state concentrations in the compartments atmosphere, surface water, soil, and sediment. In this review we discuss SB4N in more detail, as a first plastic implementation has already been made for this model (Fig. 3). SB4N models the partitioning between dissolved and particulate forms of the chemical as nonequilibrium colloidal behavior, instead of equilibrium speciation. Within each compartment, particles can occur in different physical-chemical forms (species): (a) freely dispersed, (b) heteroaggregated with natural colloidal particles, smaller than $450 \mathrm{~nm}$, or (c) attached to natural particles larger than $450 \mathrm{~nm}$. All these particle forms are subject to gravitational forces in aqueous media. Because SB4N is a spreadsheet model, it can easily be implemented for plastic debris of all sizes, as long as the parameter values are known. One of the advantages is that the model stems from SimpleBox, which is an established model already used in the risk assessment of chemicals [108]. A limitation is that the model only calculates average background concentrations.

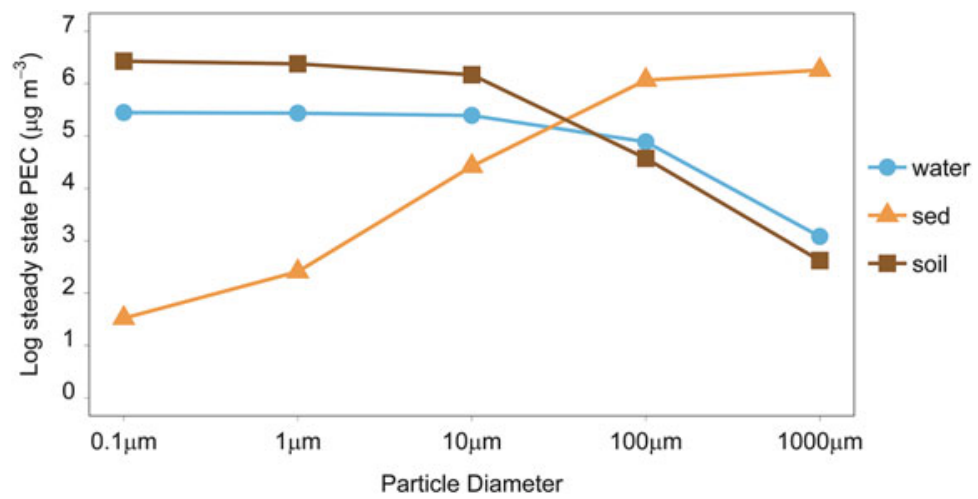

Fig. 3 Multimedia distribution of plastic debris of size $100 \mathrm{~nm}$ to $1 \mathrm{~mm}$, between atmosphere, soil, water, and sediment on a regional scale, for the river Rhine catchment, simulated with SB4N $[72,73]$. Concentrations are given on the log scale. Predicted environmental concentrations (PEC) assume a yearly emission in the catchment of $20 \mathrm{kt}$ (based on data provided in [107]) in total, a (fouled) plastic density of $1,100 \mathrm{~kg} / \mathrm{m}^{3}$, negligible degradation and fragmentation due to short particle residence time in the system, and an attachment efficiency for heteroaggregation of 0.01 [35, 36] 
We provide a first implementation for plastic in SB4N in this review (Fig. 3), which has not been published before. SB4N was parameterized for the river Rhine catchment, assuming initial emissions to the compartments soil and surface water of $50 \%$ of total emission, each. We assumed that no direct emission to sediment occurs, implying that plastic particles reach the sediment only through settling from the water column. Further assumptions are provided in the caption of Fig. 3. With all parameters at the same value, an increase in particle diameter results in more removal from water and soil and increased concentrations in sediment (more settling, Fig. 3).

\subsection{Spatiotemporally Explicit Models}

To date, two models have been presented that are able to simulate the transport of plastic debris in freshwater rivers with high spatial and temporal resolution [3537]. Both models are framed by the authors as theoretical models, that is, they are supposed to be valid with respect to the design criteria and in agreement with existing theory, but they are not yet validated against measured data for plastic debris (Table 1).

Modeling the Transport of Plastic Debris in the Dommel River (The Netherlands) The model by Besseling et al. $[35,36]$ is the first model that simulated the fate of nano- up to centimeter (i.e., macroplastic)-sized plastic particles in a river (see [24] for review). The model is based on the NanoDUFLOW hydrological model [96, 109] and includes advective transport of particles, their homo- and heteroaggregation, biofouling, sedimentation/resuspension, degradation of plastic, and burial in the sediment. This implies that all processes mentioned in Sect. 3 were accounted for. Although not yet formally validated for plastic particles because of lacking monitoring data, earlier model simulations for nano- $\mathrm{CeO}_{2}$ showed good agreement with measured nano- $\mathrm{CeO}_{2}$ submicron particles in the same river [96]. The model can be implemented for other catchments using DUFLOW Modeling Studio [110] and allows for the inclusion of tributaries and diffuse as well as point sources (e.g., WWTPs) [96].

To simulate the transport of plastic debris, parameter values were set based on literature data. Data for the attachment efficiency for heteroaggregation are scarce and therefore were also determined experimentally. A $40 \mathrm{~km}$ stretch of the river Dommel (the Netherlands) was modeled with a spatial resolution of 477 sections of an average $87.7 \mathrm{~m}$ length and with section widths ranging from 8 to $228 \mathrm{~m}$. The effect of all processes was calculated per section and the result was passed on to the next. An upstream point source with known mass concentration was used as a boundary condition at time zero, based on an average order of magnitude of published concentrations of microplastics in freshwaters. Scenario studies aimed at identifying how plastic debris of all sizes and densities would be distributed along the river. Realistic flow data were used. Impacts of long-term variability in 
weather conditions were not accounted for given the short simulation times required to reach steady state in the water column.

The scenario studies showed that the attachment efficiency to suspended solids or other plastic particles, biofilm formation on the plastic particles, and polymer type of the plastic particles had only a small effect on the modeled fate and retention [36]. Particle size, however, had a much stronger effect. Both the occurrence of accumulation "hot spots" in river sediment and overall retention in the $40 \mathrm{~km}$ river stretch were found to be highly affected by particle size. The larger micro- and millimeter-sized plastic particles showed high up to complete retention in the river due to direct Stokes settling [36]. Nanoplastic appeared to be retained and transported to an equal extent, due to the predicted fast heteroaggregation with natural solids. These solids have a higher density than the plastic and the water, causing subsequent sedimentation of these aggregates that captured the plastic particles. Retention, however, was lowest for the intermediate size class of plastic particles around $5(1-10) \mu \mathrm{m}$ due to the trade-off between these "direct" and "indirect heteroaggregate" Stokes settling mechanisms. The authors emphasized the importance of this size selection mechanism in rivers. The model was also applied to particles with a density equal to water, which resulted in no particle settling. This scenario was taken as a proxy for buoyant particles.

Freshwater organisms might be exposed relatively more to such intermediate size classes, whereas they would be depleted in the mixture of particles that is exported to sea under discontinuous input regimes [36]. The fact that the model accounted for all known processes that are relevant and that it was in agreement with data for another particle type (nano- $\mathrm{CeO}_{2}$ submicron particles [96]) contributes to the credibility of the results. The model however was set up for (near-) spherical particles. This means that it is already applicable for spherules, microbeads, or secondary plastics (e.g., car tire dust) that can be assumed to approach sphericity, but it may not yet simulate particles with diverging shapes like fibers or thin films with the same level of accuracy. Furthermore, parameters for heteroaggregation are still poorly known, which also calls for further refinement.

Modeling the Transport of Microplastic Debris in the Thames River Catchment (UK) Nizzetto et al. presented a spatiotemporally explicit model that was applied to the Thames River catchment [37]. The study is framed as purely theoretical as empirical data on microplastic emissions and concentrations were not available. The model is based on an existing hydrobiogeochemical multimedia model, INCAcontaminants [93], with a sediment transport module [95], a rainfall-runoff module [94], and the possibility to add direct effluent inputs from, for instance, WWTPs. It is a lumped model as it assumes homogeneous rainfall and temperature distributions.

The model accounted for surface runoff and effluent inputs and reentrance to the system by resuspension. Whether particles are transported by surface runoff depended on the microplastic pool available for mobilization, the transport capacity of the overland flow both for microplastics and sediment, and the detachment of plastics through splash erosion and flow erosion. In the stream, the particles are 
assumed to be uniformly mixed within each section, and the transport processes advection, settling, and size-dependent resuspension from the sediment bed were taken into account.

Microplastic properties were defined by dimension and density. The study assumed plastic particles were pristine, that is, effects of biofouling were not taken into account. The model showed that the transport of microplastics is strongly related to flow regimes, especially for the larger $(>0.2 \mathrm{~mm})$ particles. The transport dynamics were more influenced by size than by density, which confirms the findings by Besseling et al. [35, 36]. Average retention of particles was size dependent, decreasing with decreasing particle size and starting with $90-100 \%$ retention for particles $>0.2 \mathrm{~mm}$. Particles $<0.2 \mathrm{~mm}$ were less well retained, and a large portion was expected to end up in the marine environment. The particle size range of the simulated particles was $0.05-0.7 \mathrm{~mm}$; densities ranged from 1,000 to $1,300 \mathrm{~kg} \mathrm{~m}^{-3}$. The model did not include biofouling, aggregation, or fragmentation. These processes influence the hydrodynamic behavior and size distribution of the particles but according to the authors should be better understood before they can be included in the model. Nanoparticles are also not included in the model yet [37].

Comparison of the Besseling (DUFLOW) and Nizzetto (INCA-Plastic) Models Both the DUFLOW and INCA-Plastic models were in accordance with their design criteria and study aim. The NanoDUFLOW model seems more complete as it includes aggregation, which has been shown to be a crucial process, especially for submicron particles $[59,60]$. The model by Besseling et al. [35, 36] also accounted for biofouling, which also has been shown to affect the settling behavior of plastic particles. Given the study aim, Besseling et al. did not provide long-term simulations that accounted for the impacts of weather conditions. However, in principle DUFLOW can accommodate point and diffuse sources like WWTPs, tributaries [96], or runoff [111]. The latter processes were already accounted for in the INCA-Plastic implementation by Nizzetto et al., which is a relevant merit of that study. Both model outcomes agree on the important effect of particle size on retention and on a high retention for particles $>0.2 \mathrm{~mm}$. A contrasting conclusion, however, is that the INCA-Plastic model predicted that smaller particles would be less well retained in the river and thus exported to sea, whereas the NanoDUFLOW model reported an increased retention again for particles smaller than $5 \mu \mathrm{m}$. This difference can be explained from the fact that NanoDUFLOW accounted for aggregation of these small plastic particles, which allowed for the simulation of the increased sedimentation of these small plastic particles captured in heteroaggregates. This emphasizes the need to include this process. It has been shown that because heteroaggregation captures virtually all free nanosized particles, uncertainty with respect to the exact parameterization of heteroaggregation is of minor importance [73, 96, 112]. The conclusions of both studies depend on the modeled scenario's and parameters' variability. Also laboratory experiments have shown that processes like biofouling and aggregation [57, 62, 84] and particle properties like density, size, and shape [52, 55] significantly influence particle fate. 


\section{Recommendations and Guidance for the Development of Fate Models for Plastic Debris from a Risk Assessment Perspective}

\subsection{Data and Knowledge Gaps with Respect to Further Model Development}

Quality Criteria for Analysis and Detection To date, few studies have measured concentrations and characteristics of plastic debris in the freshwater environment, which implies that more and also better data are of utmost importance. Quality assurance criteria are common in analytical chemistry or ecotoxicology [113, 114] but are less self-evident for monitoring of plastic debris which is a relatively young field of science [115].

There also is an urgent need to standardize the units used to quantify abundance of plastic debris [81]. For instance, for freshwater systems, concentrations of plastics in water and sediment have until now been reported in mass per unit of volume of water [13], mass per mass of sediment [15], particles per volume of water [13, 19], particles per surface area of water [18, 19, 83, 116], and particles per mass of sediment [15]. Utility of data for modeling would improve enormously if studies would at least mention both mass and particle count data and, when taking water samples, mention the sampling depth and sampling net dimensions, which would enable a surface-to-volume conversion or vice versa. This conversion only holds under the assumption that particles are evenly distributed over the sampled depth, which is also often assumed in models.

Depending on the aims of the modeling, measured plastic abundances should meet specific requirements. To validate mass flow analysis, an estimate of the total mass of plastic per unit of volume of the modeled media would be required. Multimedia models like SB4N [72] model the free, $<0.45 \mu \mathrm{m}$ aggregated, and $>0.45 \mu \mathrm{m}$ aggregated species, and validation ideally would require mass concentrations for these size classes. Because the latter models start with emission data, i.e., from production figures, the modeling will usually relate to a specific polymer type. For deterministic spatiotemporally explicit modeling, sufficient detail with respect to actual size and polymer density distributions is required because such approaches aim to simulate the reality as closely as possible. This implies that analysis and characterization of plastic in environmental samples would need to include (a) sufficient detail in the particle size and density distributions and (b) sufficient detail in the classification of shape, i.e., like fibers, fragments, and spherules [81]. What is to be considered as "sufficient" in this respect depends on the more specific aim of the modeling and is beyond the scope of this review. Given that particle interactions as well as potential ecological effects across different species traits are size dependent, standardization of methods, including those for nano- and micrometer-sized plastic particles, is considered very important. 
Recommendation for Model Validation Validation would require sufficient data to verify the credibility of the model with statistical rigor. For mass flow or multimedia models, limited data per system yet for a high number of aquatic systems would be preferred. For spatiotemporally resolved models, however, it would be preferred to sample one catchment in detail. Such a case study catchment could then be used to calibrate and validate models, which could later be applied to other catchments. As for process parameters, little is known yet especially about the time scales of aggregation, fragmentation, and biofouling. This means that experimental work is needed, after which the parameter values obtained from these experiments can be applied in models. The development of fate models for freshwater may also benefit from experimental and model studies on marine plastic aggregation, fragmentation, and biofouling.

\subsection{Comparing the Models: What Model for Which Question?}

In the previous sections, we described different categories of models in detail. Here, we briefly discuss what category of model is needed for which type of question or application. In essence, this categorization does not differ from that for soluble chemicals or engineered nanomaterials.

For emission-based regional estimates of environmental concentrations of plastic debris, mass balance, mass flow, and especially mechanistic multimedia models are adequate. Recently, for nanoparticles such models have been developed, like the SB4N model [63, 72, 73] and the MendNano model [106]. It is highly recommended that such mechanistic multimedia models are adapted for plastic as well. Being neither temporal nor spatially explicit, such models are screening level models that can be used to assess relative concentrations among classes of nanoand microplastics or among plastic emission scenarios. Hence, such models are useful to calculate regional average or background concentrations (PECs, predicted environmental concentrations) for different plastic types, for different regions, or for different future emission scenarios. Multimedia particle models can also be used to detect the parameters to which the model output is most sensitive or to quantify uncertainty in PECs, which than can be applied in probabilistic risk assessments (discussed below).

Compared to the output provided by multimedia models, more realistic estimates of local environmental fate and concentrations can be obtained with spatiotemporally explicit models. However, fate models that are spatially explicit only yield better estimates if data on spatial variability in emission intensities are available. At present, there is only limited information on such spatial variation. Furthermore, estimating regional average concentrations still requires definition of what is defined as "a region." Different models use different scales, which means that the research question defines what model is most adequate. Global river models like 
Global NEWS link mass flow models for river catchments, which thus accounts for spatial variation among catchments on a global scale, but not within catchments [91, 117]. As for applications, such models can rank catchments, regions, countries, or continents with respect to emission intensity to the marine environment [92]. The multimedia model SB4N can also accommodate various spatial scales, like regional, continental, and global, but always calculates one average concentration for soil, sediment, air, lake, river, and seawater. It is possible, however, to run models like SB4N for a certain grid, within an overarching model that provides input on a scale of, for instance, $200 \times 200 \mathrm{~km}$ [118].

For more accurate local estimates of concentrations of plastic debris, systemspecific zero-D mass balance approaches can be used for smaller systems, like lakes [63]. However, to better account for variability, spatiotemporally explicit models in 1, 2, or 3 dimensions can be used. As far as we know, the 1-D NanoDUFLOW model discussed above is the most elaborated model available. By defining small segments in a river, full hydrology can be taken into account. This is important for answering questions with respect to "hot spot" locations, quantifying which plastic types and sizes can be expected where (including nanosized plastic), calculation of retention versus flow-through to sea, and prospective assessments of fate and exposure on a detailed local scale. It has been argued recently that such models may be able to predict biologically relevant nanoparticle aggregate species as a function of time and space, which in turn can be linked to exposure by biota inhabiting the water system in question [24]. We propose that a similar approach also is possible for plastic debris, although further validation of fate models as well as further assessment of what has to be considered bioavailable and ecologically relevant is required. These last steps are particularly important when models are used in the framework of a formal risk assessment.

\subsection{Fate and Exposure Models in the Context of ERA for Plastic in Freshwater Systems}

To date, no ERA framework has been defined or applied to plastic debris. Here, we postulate that for plastic debris the same basic components of ERA can be used as for traditional chemicals and engineered nanomaterials: problem definition stage, an exposure assessment, an effect assessment, and a risk characterization step $[119,120]$. For plastic debris, exposure presently is difficult to measure, so there is a relatively high need for modeling tools. A crucial aspect of exposure modeling and effect assessment in the context of ERA is what is to be considered the "ecotoxicologically relevant metric" (ERM) [120]. The ERM is the "common currency" used in the exposure and the effect assessment, which links these two, such that they can lead to a consistent risk characterization. For soluble chemicals, the ERM always is concentration, which is why ERA for chemicals uses the 
ecotoxicologically relevant concentration. Effect assessment and risk characterization are beyond the scope of this review, which focuses on freshwater models for fate and exposure (see [121] for details). However, in order to frame models in the context of ERA, here we briefly touch upon the wide variety of adverse outcome pathways (AOPs) that exists for plastic debris. As plastic debris is a complex mixture of sizes, types, and shapes, which also can be associated with chemicals, there will be a multitude of ERMs. Each ERM captures the unique features of a particular type of debris present in a habitat in combination with specific traits of species in that habitat, leading to an AOP describing the preset ecological or human health protection goals. Some reported AOPs are entanglement, ingestion/suffocation, blockage of the gastrointestinal tract, food dilution, chemical toxicity from associated chemicals, and a series of biomarker responses, which have been reviewed recently $[6,9,122]$. ERMs for physical effect of plastic can be defined in the form of a matrix where exposure and effect criteria such as habitat, species, life stage, mode of action, plastic size, plastic shape, and exposure duration are tabulated and scored. Using population models, effects on individuals then can be integrated with those from other stressors and habitat factors and, where needed, scaled to the population level similar to pesticide effect models (e.g., [100]). The ERM then needs to be assessed in space and time, dependent on the protection goal and the aim of the ERA. Ideally, fate models as described in this review should thus be able to simulate or predict all relevant ERMs emerging from the broad suite of species and particles that can be encountered in a habitat that has to be protected. Here, as mentioned before, for relatively simple site or material prioritizations, regional background concentrations as produced by multimedia models may suffice. Multimedia models can also be used in probabilistic ERA where spatial heterogeneity is accounted for by using a probability function that quantifies the spatial variation. For site-specific assessments, ERMs may be predicted by explicit models like NanoDUFLOW [36, 96], INCA-contaminants [93], or similar particle models, as long as aggregation of nanosized particle fractions is accounted for. Exposure then can be combined with effect thresholds in a PEC/NEC (NEC is the no-effect concentration) approach, where the NEC may come from data for different dose response models dependent on the AOP (threshold model, log logistic, Weibull, binary). Due to considerable uncertainty compared to ERA for traditional chemicals, probabilistic approaches are recommended, which can be adopted from recent developments in the ERA of engineered nanoparticles [118].

\section{Concluding Thoughts}

Contamination of the freshwater environment with plastic debris of all sizes has received increasing attention. In this review we argue that in order to conduct a proper risk assessment of plastic pollutants and their sources, and given the scarcity of data, models are useful complementary methods for exposure assessment. These models can build on existing transport models that simulate other types of particles, 
only changing the plastics-specific parameters and characteristics. As a material to model, plastic is unique given its wide range of sizes, shapes, and densities. It can aggregate or fragment and obtain a biofilm, all of which influence the hydrodynamics and size distribution of the particles. The first models developed for plastic transport so far range from mass-balance point-emission models to spatiotemporally explicit models. These models, however, have not yet been calibrated because of a lack of data. We recommend that before large measurement campaigns start, units to express abundance of plastics and methods for the analysis of plastics in the environment are standardized, which would increase the usability of the measurements.

Acknowledgment This study was funded by the Dutch Technology Foundation STW, project nr 13940. We acknowledge additional support from KWR; IMARES; NVWA; RIKILT; the Dutch Ministry of Infrastructure and the Environment; the Dutch Ministry of Health, Welfare and Sport; Wageningen Food \& Biobased Research; STOWA; RIWA; and water boards Hoogheemraadschap van Delfland, Zuiderzeeland, Rijn en IJssel, Vechtstromen, Scheldestromen, Aa en Maas, de Dommel, and Rivierenland.

\section{References}

1. Andrady AL (2011) Microplastics in the marine environment. Mar Pollut Bull 62:1596-1605. doi:10.1016/j.marpolbul.2011.05.030

2. Rochman CM, Cook A-M, Koelmans AA (2016) Plastic debris and policy: using current scientific understanding to invoke positive change. Environ Toxicol Chem 35:1617-1626

3. Eriksen M, Lebreton LCM, Carson HS et al (2014) Plastic pollution in the world's oceans: more than 5 trillion plastic pieces weighing over 250,000 tons afloat at sea. PLoS One:1-15. doi:10.1371/journal.pone.0111913

4. Jambeck JR, Geyer R, Wilcox C et al (2015) Plastic waste input from land into the ocean. Science 80(347):768-771

5. Huerta Lwanga E, Gertsen H, Gooren H et al (2016) Microplastics in the terrestrial ecosystem: implications for Lumbricus terrestris (Oligochaeta, Lumbricidae). Environ Sci Technol 50:2685-2691

6. Kühn S, Rebolledo ELB, van Franeker JA (2015) Deleterious effects of litter on marine life. In: Bergmann M, Gutow L, Klages M (eds) Marine anthropogenic litter. Springer, Berlin, pp 75-116

7. Cole M, Lindeque P, Fileman E et al (2013) Microplastic ingestion by zooplankton. Environ Sci Technol 47:6646-6655. doi:10.1021/es400663f

8. Scherer $\mathrm{C}$ et al (2017) Interactions of microplastics with freshwater biota. In: Wagner M, Lambert S (eds) Freshwater microplastics: emerging environmental contaminants? Springer Nature, Heidelberg. doi:10.1007/978-3-319-61615-5_8 (in this volume)

9. Koelmans AA, Bakir A, Burton GA, Janssen CR (2016) Microplastic as a vector for chemicals in the aquatic environment: critical review and model-supported reinterpretation of empirical studies. Environ Sci Technol 50:3315-3326

10. Barnes DKA (2002) Biodiversity: invasions by marine life on plastic debris. Nature 416: 808-809 
11. Lusher AL, Tirelli V, O'Connor I, Officer R (2015) Microplastics in Arctic polar waters: the first reported values of particles in surface and sub-surface samples. Sci Rep 5:14947

12. Van Cauwenberghe L, Vanreusel A, Mees J, Janssen CR (2013) Microplastic pollution in deep-sea sediments. Environ Pollut 182:495-499. doi:10.1016/j.envpol.2013.08.013

13. Lechner A, Keckeis H, Lumesberger-Loisl F et al (2014) The Danube so colourful: a potpourri of plastic litter outnumbers fish larvae in Europe's second largest river. Environ Pollut 188:177-181

14. Rech S, Macaya-Caquilpán V, Pantoja JF et al (2014) Rivers as a source of marine litter-a study from the SE Pacific. Mar Pollut Bull 82:66-75

15. Klein S, Worch E, Knepper TP (2015) Occurrence and spatial distribution of microplastics in river shore sediments of the Rhine-main area in Germany. Environ Sci Technol 49: 6070-6076

16. Wagner M, Scherer C, Alvarez-Muñoz D et al (2014) Microplastics in freshwater ecosystems: what we know and what we need to know. Environ Sci Eur 26(1):1-9

17. Eerkes-Medrano D, Thompson RC, Aldridge DC (2015) Microplastics in freshwater systems: a review of the emerging threats, identification of knowledge gaps and prioritisation of research needs. Water Res 75:63-82

18. Free CM, Jensen OP, Mason SA et al (2014) High-levels of microplastic pollution in a large, remote, mountain lake. Mar Pollut Bull 85:156-163

19. Mani T, Hauk A, Walter U, Burkhardt-Holm P (2015) Microplastics profile along the Rhine river. Sci Rep 5:17988

20. Castañeda RA, Avlijas S, Simard MA, Ricciardi A (2014) Microplastic pollution in St. Lawrence river sediments. Can J Fish Aquat Sci 71:1767-1771

21. Dris R, Gasperi J, Saad M et al (2016) Synthetic fibers in atmospheric fallout: a source of microplastics in the environment? Mar Pollut Bull 104:290-293

22. Faure F, Demars C, Wieser O et al (2015) Plastic pollution in Swiss surface waters: nature and concentrations, interaction with pollutants. Environ Chem 12:582-591

23. Morritt D, Stefanoudis PV, Pearce D et al (2014) Plastic in the Thames: a river runs through it. Mar Pollut Bull 78:196-200

24. Koelmans AA, Besseling E, Shim WJ (2015) Nanoplastics in the aquatic environment. Critical review. In: Marine anthropogenic litter. Springer, Berlin, pp 325-340

25. Mattsson K, Hansson L-A, Cedervall T (2015) Nano-plastics in the aquatic environment. Environ Sci Process Impacts 17:1712-1721

26. Cole M, Galloway TS (2015) Ingestion of nanoplastics and microplastics by Pacific oyster larvae. Environ Sci Technol 49:14625-14632

27. Gigault J, Pedrono B, Maxit B, Ter Halle A (2016) Marine plastic litter: the unanalyzed nanofraction. Environ Sci Nano 3:346-350

28. Lambert S, Wagner M (2016) Characterisation of nanoplastics during the degradation of polystyrene. Chemosphere 145:265-268

29. Rist SE, Hartmann NB (2017) Aquatic ecotoxicity of microplastics and nanoplasticslessons learned from engineered nanomaterials. In: Wagner M, Lambert S (eds) Freshwater microplastics: emerging environmental contaminants? Springer, Heidelberg. doi:10.1007/ 978-3-319-61615-5_2 (in this volume)

30. da Costa JP, Santos PSM, Duarte AC, Rocha-Santos T (2016) (Nano) plastics in the environment- sources, fates and effects. Sci Total Environ 566:15-26

31. Sanchez W, Bender C, Porcher J-M (2014) Wild gudgeons (Gobio gobio) from French rivers are contaminated by microplastics: preliminary study and first evidence. Environ Res 128: 98-100

32. Phillips MB, Bonner TH (2015) Occurrence and amount of microplastic ingested by fishes in watersheds of the Gulf of Mexico. Mar Pollut Bull 100:264-269

33. Peters CA, Bratton SP (2016) Urbanization is a major influence on microplastic ingestion by sunfish in the Brazos River Basin, Central Texas, USA. Environ Pollut 210:380-387 
34. Imhof HK, Laforsch C (2016) Hazardous or not- are adult and juvenile individuals of Potamopyrgus antipodarum affected by non-buoyant microplastic particles? Environ Pollut 218: 383-391

35. Besseling E, Quik JTK, Koelmans AA (2014) Modeling the fate of nano- and microplastics in freshwater systems. SETAC Annual Meeting, Basel, Switzerland. doi: 10.13140/RG.2.2. 20991.61602

36. Besseling E, Quik JTK, Sun M, Koelmans AA (2017) Fate of nano- and microplastic in freshwater systems: a modeling study. Environ Pollut 220:540-548

37. Nizzetto L, Bussi G, Futter MN et al (2016) A theoretical assessment of microplastic transport in river catchments and their retention by soils and river sediments. Environ Sci Process Impacts 18:1050-1059

38. Gasperi J, Dris R, Bonin T et al (2014) Assessment of floating plastic debris in surface water along the Seine River. Environ Pollut 195:163-166

39. Merritt WS, Letcher RA, Jakeman AJ (2003) A review of erosion and sediment transport models. Environ Model Softw 18:761-799. doi:10.1016/S1364-8152(03)00078-1

40. Aksoy H, Kavvas ML (2005) A review of hillslope and watershed scale erosion and sediment transport models. Catena 64:247-271

41. Drewry JJ, Newham LTH, Greene RSB et al (2006) A review of nitrogen and phosphorus export to waterways: context for catchment modelling. Mar Freshw Res 57:757-774

42. Vanderkruk K, Owen K, Grace M, Thompson R (2009) Review of existing nutrient, Suspended Solid and Metal Models

43. Whitehead PG, Howard A, Arulmani C (1997) Modelling algal growth and transport in rivers: a comparison of time series analysis, dynamic mass balance and neural network techniques. Hydrobiologia 349:39-46

44. Vermeulen LC, Hofstra N, Kroeze C, Medema G (2015) Advancing waterborne pathogen modelling: lessons from global nutrient export models. Curr Opin Environ Sustain 14: $109-120$

45. Gottschalk F, Sun T, Nowack B (2013) Environmental concentrations of engineered nanomaterials: review of modeling and analytical studies. Environ Pollut 181:287-300

46. Baalousha M, Cornelis G, Kuhlbusch TAJ et al (2016) Modeling nanomaterial fate and uptake in the environment: current knowledge and future trends. Environ Sci Nano 3: 323-345

47. Ji Z-G (2008) Hydrodynamics and water quality: modeling rivers, lakes, and estuaries. Wiley, Hoboken

48. Fischer HB, List JE, Koh CR et al (2013) Mixing in inland and coastal waters. Elsevier, Amsterdam

49. Wallis S (2007) The numerical solution of the advection-dispersion equation: a review of some basic principles. Acta Geophys 55:85-94

50. Ani E-C, Wallis S, Kraslawski A, Agachi PS (2009) Development, calibration and evaluation of two mathematical models for pollutant transport in a small river. Environ Model Softw 24:1139-1152

51. Brown PP, Lawler DF (2003) Sphere drag and settling velocity revisited. J Environ Eng 129: 222-231. doi:10.1061/(ASCE)0733-9372(2003)129:3(222)

52. Kowalski N, Reichardt AM, Waniek JJ (2016) Sinking rates of microplastics and potential implications of their alteration by physical, biological, and chemical factors. Mar Pollut Bull 109(1):310-319

53. McNown JS, Malaika J (1950) Effects of particle shape on settling velocity at low Reynolds numbers. EOS Trans Am Geophys Union 31:74-82

54. Johnson CP, Li X, Logan BE (1996) Settling velocities of fractal aggregates. Environ Sci Technol 30:1911-1918 
55. Khatmullina L, Isachenko I (2016) Settling velocity of microplastic particles of regular shapes. Mar Pollut Bull 114(2):871-880

56. Farley KJ, Morel FMM (1986) Role of coagulation in the kinetics of sedimentation. Environ Sci Technol 20:187-195

57. Long M, Moriceau B, Gallinari M et al (2015) Interactions between microplastics and phytoplankton aggregates: impact on their respective fates. Mar Chem 175:39-46. doi:10.1016/j. marchem.2015.04.003

58. Chubarenko I, Bagaev A, Zobkov M, Esiukova E (2016) On some physical and dynamical properties of microplastic particles in marine environment. Mar Pollut Bull 108(2):105-112

59. Praetorius A, Scheringer M, Hungerbühler K (2012) Development of environmental fate models for engineered nanoparticles- a case study of $\mathrm{TiO} 2$ nanoparticles in the Rhine river. Environ Sci Technol 46:6705-6713

60. Quik JTK, Velzeboer I, Wouterse M et al (2014) Heteroaggregation and sedimentation rates for nanomaterials in natural waters. Water Res 48:269-279

61. Lee DG, Bonner JS, Garton LS et al (2000) Modeling coagulation kinetics incorporating fractal theories: a fractal rectilinear approach. Water Res 34:1987-2000. doi:10.1016/S00431354(99)00354-1

62. Fazey FMC, Ryan PG (2016) Biofouling on buoyant marine plastics: an experimental study into the effect of size on surface longevity. Environ Pollut 210:354-360

63. Koelmans AA, Quik JTK, Velzeboer I (2015) Lake retention of manufactured nanoparticles. Environ Pollut 196:171-175

64. Mahmood K (1987) Reservoir sedimentation: impact, extent, and mitigation. Technical paper

65. HJ Q, Kroeze C (2010) Past and future trends in nutrients export by rivers to the coastal waters of China. Sci Total Environ 408:2075-2086

66. HJ Q, Kroeze C (2012) Nutrient export by rivers to the coastal waters of China: management strategies and future trends. Reg Environ Chang 12:153-167

67. FAO (2016) AQUASTAT website. Food and Agriculture Organization of the United Nations (FAO), Rome

68. Weilenmann U, O'Melia CR, Stumm W (1989) Particle transport in lakes: models and measurements. Limnol Oceanogr 34:1-18

69. Papanicolaou A, Thanos N, Elhakeem M, Krallis G et al (2008) Sediment transport modeling review—current and future developments. J Hydraul Eng 134:1-14

70. Cushing CE, Minshall GW, Newbold JD (1993) Transport dynamics of fine particulate organic matter in two Idaho streams. Limnol Oceanogr 38:1101-1115

71. Boling RH, Goodman ED, Van Sickle JA et al (1975) Toward a model of detritus processing in a woodland stream. Ecology 56:141-151

72. Meesters JAJ, Koelmans AA, Quik JTK et al (2014) Multimedia modeling of engineered nanoparticles with simpleBox4nano: model definition and evaluation. Environ Sci Technol 48:5726-5736. doi:10.1021/es500548h

73. Meesters JAJ, Quik JTK, Koelmans AA et al (2016) Multimedia environmental fate and speciation of engineered nanoparticles: a probabilistic modeling approach. Environ Sci Nano 3:715-727

74. Merritt DM, Wohl EE (2002) Processes governing hydrochory along rivers: hydraulics, hydrology, and dispersal phenology. Ecol Appl 12:1071-1087

75. Bridge JS, Bennett SJ (1992) A model for the entrainment and transport of sediment grains of mixed sizes, shapes, and densities. Water Resour Res 28:337-363

76. Michels J, Stippkugel A, Wirtz K, Engel A (2015) Aggregation of microplastics with marine biogenic particles. ASLO Aquatic Sciences Meeting 2015

77. Burd AB, Jackson GA (2009) Particle aggregation. Annu Rev Mar Sci 1:65-90

78. Hotze EM, Phenrat T, Lowry G V (2010) Nanoparticle aggregation: challenges to understanding transport and reactivity in the environment. J Environ Qual 39:1909-1924 
79. Zhang K, Gong W, Lv J et al (2015) Accumulation of floating microplastics behind the Three Gorges Dam. Environ Pollut 204:117-123

80. Wright SL, Thompson RC, Galloway TS (2013) The physical impacts of microplastics on marine organisms: a review. Environ Pollut 178:483-492. doi:10.1016/j.envpol.2013.02.031

81. Dris R, Imhof H, Sanchez W et al (2015) Beyond the ocean: contamination of freshwater ecosystems with (micro-) plastic particles. Environ Chem 12:539-550

82. Williams AT, Simmons SL (1996) The degradation of plastic litter in rivers: implications for beaches. J Coast Conserv 2:63-72

83. Eriksen M, Mason S, Wilson S et al (2013) Microplastic pollution in the surface waters of the Laurentian Great Lakes. Mar Pollut Bull 77:177-182

84. Lagarde F, Olivier O, Zanella M et al (2016) Microplastic interactions with freshwater microalgae: hetero-aggregation and changes in plastic density appear strongly dependent on polymer type. Environ Pollut 215:331-339

85. Van Cauwenberghe L (2016) Occurrence, effects and risks of marine microplastics. Ghent University, Gent

86. Van Rijn LC (1984) Sediment transport, part II: suspended load transport. J Hydraul Eng 110: 1613-1641

87. Barnes DKA, Galgani F, Thompson RC, Barlaz M (2009) Accumulation and fragmentation of plastic debris in global environments. Philos Trans R Soc Lond Ser B Biol Sci 364: 1985-1998. doi:10.1098/rstb.2008.0205

88. Klein S et al (2017) Analysis, occurrence, and degradation of microplastics in the aqueous environment. In: Wagner M, Lambert S (eds) Freshwater microplastics: emerging environmental contaminants? Springer, Heidelberg. doi:10.1007/978-3-319-61615-5_3 (in this volume)

89. Corcoran PL, Norris T, Ceccanese T et al (2015) Hidden plastics of Lake Ontario, Canada and their potential preservation in the sediment record. Environ Pollut 204:17-25

90. van Wezel A, Caris I, Kools S (2015) Release of primary microplastics from consumer products to wastewater in The Netherlands. Environ Toxicol Chem 35:1627-1631

91. Siegfried M, Verburg C, Gabbert S, et al (2016) Modelling river export of micro- and macro plastics from land to sea. EGU General Assembly Conference Poster

92. Siegfried M, Gabbert S, Koelmans AA, et al (2016) River export of plastic from land to sea: a global modeling approach. In: EGU General Assembly Conference Abstract. p 11507

93. Nizzetto L, Butterfield D, Futter M et al (2016) Assessment of contaminant fate in catchments using a novel integrated hydrobiogeochemical-multimedia fate model. Sci Total Environ 544:553-563

94. Futter MN, Erlandsson MA, Butterfield D et al (2014) PERSiST: a flexible rainfall-runoff modelling toolkit for use with the INCA family of models. Hydrol Earth Syst Sci 18:855-873

95. Lazar AN, Butterfield D, Futter MN et al (2010) An assessment of the fine sediment dynamics in an upland river system: INCA-Sed modifications and implications for fisheries. Sci Total Environ 408:2555-2566

96. de Klein JJM, Quik JTK, Bäuerlein PS, Koelmans AA (2016) Towards validation of the NanoDUFLOW nanoparticle fate model for the river Dommel, The Netherlands. Environ Sci Nano 3:434-441

97. Hollander A, Schoorl M, van de Meent D (2016) SimpleBox 4.0: improving the model while keeping it simple. Chemosphere 148:99-107

98. Gottschalk F, Sonderer T, Scholz RW, Nowack B (2009) Modeled environmental concentrations of engineered nanomaterials ( $\mathrm{TiO} 2, \mathrm{ZnO}, \mathrm{Ag}, \mathrm{CNT}$, fullerenes) for different regions. Environ Sci Technol 43:9216-9222

99. Keller AA, Vosti W, Wang H, Lazareva A (2014) Release of engineered nanomaterials from personal care products throughout their life cycle. J Nanopart Res 16:1-10 
100. Gouin T, Avalos J, Brunning I et al (2015) Use of micro-plastic beads in cosmetic products in Europe and their estimated emissions to the North Sea environment. SOFW-J 141:40-46

101. Mayorga E, Seitzinger SP, Harrison JA et al (2010) Global nutrient export from WaterSheds 2 (NEWS 2): model development and implementation. Environ Model Softw 25:837-853

102. Seitzinger SP, Mayorga E, Bouwman AF et al (2010) Global river nutrient export: a scenario analysis of past and future trends. Global Biogeochem Cycles 24:GB0A08

103. Fekete BM, Wisser D, Kroeze C et al (2010) Millennium ecosystem assessment scenario drivers (1970-2050): climate and hydrological alterations. Global Biogeochem Cycles 24(4). doi:10.1029/2009GB003593

104. Bouwman AF, Beusen AHW, Billen G (2009) Human alteration of the global nitrogen and phosphorus soil balances for the period 1970-2050. Global Biogeochem Cycles 23(4). doi:10.1029/2009GB003576

105. Van Drecht G, Bouwman AF, Harrison J, Knoop JM (2009) Global nitrogen and phosphate in urban wastewater for the period 1970 to 2050. Global Biogeochem Cycles 23(4). doi:10. 1029/2009GB003458

106. Liu HH, Cohen Y (2014) Multimedia environmental distribution of engineered nanomaterials. Environ Sci Technol 48:3281-3292

107. Sherrington C, Darrah C, Hann S et al (2016) Study to support the development of measures to combat a range of marine litter sources. Report for European commission DG environment. Eunomia Research \& Consulting, Bristol

108. Meesters JAJ, Veltman K, Hendriks AJ, van de Meent D (2013) Environmental exposure assessment of engineered nanoparticles: why REACH needs adjustment. Integr Environ Assess Manag 9:e15-e26

109. Quik JTK, de Klein JJM, Koelmans AA (2015) Spatially explicit fate modelling of nanomaterials in natural waters. Water Res 80:200-208

110. Clemmens AJ, Holly FM Jr, Schuurmans W (1993) Description and evaluation of program: duflow. J Irrig Drain Eng 119:724-734

111. David I, Beilicci E, Beilicci R (2015) Basics for hydraulic modelling of flood runoff using advanced hydroinformatic tools. In: Extreme weather and impacts of climate change on water resources in the Dobrogea region. IGI Global, pp 205-239

112. Dale AL, Lowry GV, Casman EA (2015) Stream dynamics and chemical transformations control the environmental fate of silver and zinc oxide nanoparticles in a watershed-scale model. Environ Sci Technol 49:7285-7293

113. Klimisch H-J, Andreae M, Tillmann U (1997) A systematic approach for evaluating the quality of experimental toxicological and ecotoxicological data. Regul Toxicol Pharmacol 25:1-5

114. Kase R, Korkaric M, Werner I, Ågerstrand M (2016) Criteria for reporting and evaluating ecotoxicity data (CRED): comparison and perception of the Klimisch and CRED methods for evaluating reliability and relevance of ecotoxicity studies. Environ Sci Eur 28(1):7

115. Rocha-Santos T, Duarte AC (2015) A critical overview of the analytical approaches to the occurrence, the fate and the behavior of microplastics in the environment. TrAC Trends Anal Chem 65:47-53

116. Imhof HK, Ivleva NP, Schmid J et al (2013) Contamination of beach sediments of a subalpine lake with microplastic particles. Curr Biol 23:R867-R868

117. Kroeze C, Gabbert S, Hofstra N et al Global modelling of surface water quality: a multipollutant approach. Curr Opin Environ Sustain 23:35-45

118. Jacobs R, Meesters JAJ, ter Braak CJF et al (2016) Combining exposure and effect modelling into an integrated probabilistic environmental risk assessment for nanoparticles. Environ Toxicol Chem 35:2958-2967

119. Klaine SJ, Koelmans AA, Horne N et al (2012) Paradigms to assess the environmental impact of manufactured nanomaterials. Environ Toxicol Chem 31:3-14

120. Koelmans AA, Diepens NJ, Velzeboer I et al (2015) Guidance for the prognostic risk assessment of nanomaterials in aquatic ecosystems. Sci Total Environ 535:141-149 
121. Brennholt $\mathrm{N}$ et al (2017) Freshwater microplastics: challenges for regulation and management. In: Wagner M, Lambert S (eds) Freshwater microplastics: emerging environmental contaminants? Springer, Heidelberg. doi:10.1007/978-3-319-61615-5_12 (in this volume)

122. Ziccardi LM, Edgington A, Hentz K et al (2016) Microplastics as vectors for bioaccumulation of hydrophobic organic chemicals in the marine environment: a state-of-the-science review. Environ Toxicol Chem 35:1667-1676

Open Access This chapter is licensed under the terms of the Creative Commons Attribution 4.0 International License (http://creativecommons.org/licenses/by/4.0/), which permits use, sharing, adaptation, distribution and reproduction in any medium or format, as long as you give appropriate credit to the original author(s) and the source, provide a link to the Creative Commons license and indicate if changes were made.

The images or other third party material in this chapter are included in the chapter's Creative Commons license, unless indicated otherwise in a credit line to the material. If material is not included in the chapter's Creative Commons license and your intended use is not permitted by statutory regulation or exceeds the permitted use, you will need to obtain permission directly from the copyright holder. 